
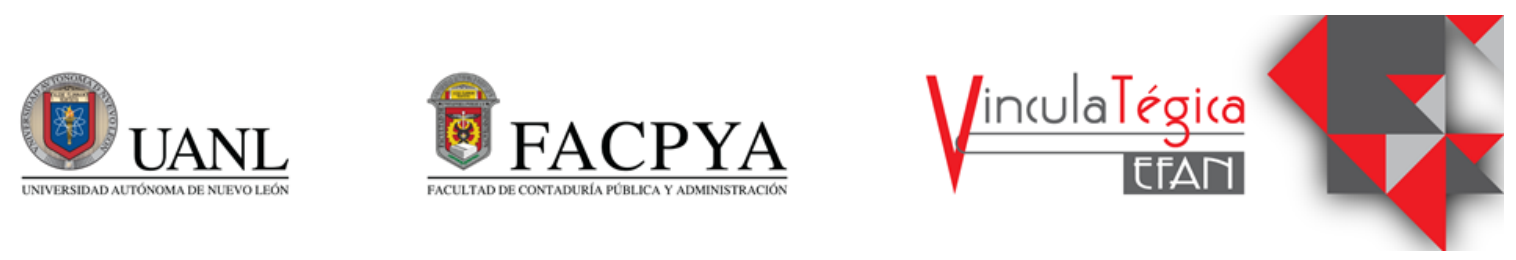

\title{
Educación financiera, una de las soluciones a la inminente crisis de pensiones en México
}

\author{
Ana Jazmín Sandoval Sánchez ${ }^{1}$ y Sósima Carrillo \\ ${ }^{1}$ Universidad Autónoma de Baja California, jazmin.sandoval93@uabc.edu.mx, Av. Álvaro Obregón S/N \\ Colonia Nueva, 6861238004 \\ ${ }^{2}$ Universidad Autónoma de Baja California, sosima@uabc.edu.mx, Av. Álvaro Obregón S/N Colonia Nueva, \\ 6861135895 \\ Información del artículo revisado por pares \\ Fecha de aceptación: junio-2021 \\ Fecha de publicación en línea: diciembre-2021 \\ DOI: https://doi.org/10.29105/vtga7.1-127
}

\section{Resumen}

La educación financiera tiene impacto en las finanzas personales y en las finanzas públicas. El presente trabajo tiene como objetivo demostrar cómo un mexicano con una educación financiera básica, puede aplicar estrategias enfocadas al manejo de su crédito INFONAVIT y las aportaciones voluntarias en su fondo de ahorro para el retiro, que le permitan aumentar la tasa de reemplazo de su pensión estimada, así como beneficios fiscales, contribuyendo con ello a mejorar su calidad de vida. El estudio se realizó mediante el método de estudio de caso, utilizando las regulaciones vigentes y los datos promedio de la economía mexicana.

Palabras clave: Educación financiera, crédito, pensión, aportaciones

\section{INTRODUCCIÓN}

En la actualidad las decisiones financieras están cobrando una mayor importancia debido a la situación económica del país y la escasez de los recursos financieros. Siendo esencial fomentar el ahorro como medio de prevención y convertirlo en un hábito que permita el logro de objetivos tanto personales como familiares
Abstract
Financial education has an impact on personal finances and public finances. The present work aims to demonstrate how a mexican with a basic financial education can apply strategies focused on managing his INFONAVIT credit and voluntary contributions in his retirement savings fund, which allow him to increase the replacement rate of his pension estimated, as well as tax benefits, thereby helping to improve his quality of life. The study was carried out using the case study method, using current regulations and average data from the mexican economy.

Keywords: Financial education, credit, pension, contributions

JEL: E43, H55, J32

(Carrillo y Lamamié, 2008). Asimismo, (Zakaria, Jaafar y Marican, 2012), señalan que las personas han recurrido al financiamiento para elevar su calidad de vida, adquiriendo productos o servicios, sin tener realmente la capacidad de pago, provocando con ello, un sobre endeudamiento.

La sobre oferta que existe de tarjetas 
de crédito en el mercado, tanto de instituciones financieras, como de tiendas departamentales, y la necesidad de las personas por hacerse de bienes y servicios, sin analizar realmente su capacidad de pago, es otro factor, que afecta a las finanzas de las personas (INEGI, 2018), lo que en ocasiones provoca que la persona no cuente con la liquidez suficiente para cumplir con sus deudas. Por ello, es necesario conocer el impacto que tienen las decisiones de las personas sobre el ahorro, inversiones y financiamiento, en el desarrollo de sus vidas. De ahí la importancia de tener un conocimiento de finanzas personales e ir formando una educación financiera desde una edad temprana, que permita tener una mejor calidad de vida.

Hoy en día, el tema del ahorro de los jóvenes para formar o aportar a sus fondos de retiro, es un tema de relevancia, considerando que, de acuerdo a las leyes vigentes, las cantidades que se aporten solo por su relación obrero-patronal, serán insuficientes para contar con un nivel de vida de calidad. Sin embargo, existe mucho desconocimiento de este tema por parte de los jóvenes, adicional a la falta de educación y cultura financiera.

Por lo tanto, se concluye que la situación actual amerita un cambio significativo por parte de sociedad y gobierno, con acciones que corrijan dicho desconocimiento.

\section{MARCO TEÓRICO}

En este apartado se plasma la importancia de la educación financiera, el conocimiento del sistema pensionario, así como la relación de ambos conceptos en el futuro financiero de un mexicano.

\subsection{Educación financiera}

De acuerdo con el Banco del Bienestar, Sociedad Nacional de Crédito, Institución de Banca de Desarrollo (2019)

La educación financiera es un proceso de desarrollo de habilidades y actitudes que, mediante la asimilación de información comprensible y herramientas básicas de administración de recursos y planeación, permiten a los individuos tomar decisiones personales y sociales de carácter económico en su vida cotidiana, y utilizar productos y servicios financieros para mejorar su calidad de vida bajo condiciones de certeza.

En un estudio realizado por MorenoGarcía, García-Santillán y Gutiérrez-Delgado (2017), para evaluar el conocimiento que tienen los estudiantes universitarios del área económico-administrativa, acerca de tasa de interés, inflación, ahorro, uso de tarjeta de crédito y elaboración de presupuestos, encontraron que los estudiantes universitarios no tienen el hábito del ahorro para tener una seguridad económica, no saben calcular tasas de interés, ni conocen el efecto que tiene la inflación en el cálculo de valuación del dinero, demostrando así un bajo nivel de educación financiera. Este concepto es esencial para que ellos mismos pudieran determinar el impacto que tendrían sus ahorros o aportaciones a su fondo de pensiones.

\subsection{Pensiones y conceptos básicos}

El esquema Beneficio Definido (BD) es aquel en que los jóvenes pagan las pensiones de las personas mayores. En el caso de México, dicho esquema es aquel que se reflejó en la ley de 1973. Sin embargo, conforme la esperanza de vida creció y aumentaron las presiones fiscales, se volvió imperativo cambiar las cosas. De hecho, la ausencia de un derecho de propiedad hizo que dichos recursos fueran utilizados para financiar el déficit de operación e infraestructura del IMSS.

Al hablar de la evolución que los esquemas pensionarios han tenido, Ramírez (2019) sostiene que entre 1981 a 2014, unos 30 países han privatizado total o parcialmente sus pensiones, cambiando a un esquema de Contribución Definida (CD). De dichos países, 14 se encuentran en América Latina, 14 más en Europa y 2 en el continente africano. Asimismo, se considera que este nuevo esquema de pensiones, aunque es una solución tentativa al problema suscitado con el esquema Beneficio Definido (BD), contribuye a mantener las dinámicas de desigualdad que ya existían de acuerdo a la brecha salarial entre 
la población, aumentando además dicha desigualdad por el riesgo inherente al ciclo de vida, el ciclo económico y a la elección de una administradora de fondos de pensión.

En México, en 1992 se dio la creación del Sistema de Ahorro para el Retiro y en 1994 se creó la Comisión Nacional del Sistema de Ahorro para el Retiro. Finalmente, el 1 de Julio de 1997 se establece la nueva Ley del IMSS, en la cual se cambia a un esquema $\mathrm{CD}$, mismo que contempla que los recursos contribuidos a la cuenta individual de cada trabajador sean los que financien la pensión. En el país aún se mantiene el régimen $\mathrm{BD}$, pero sólo en estados, empresas productivas del estado (antes paraestatales) e instituciones de la banca de desarrollo.

\subsection{La inminente crisis de pensiones en México}

De acuerdo con Ramírez (2017) los retos más importantes en materia de pensiones no son exclusivos de México, sino que se presentan de manera global. Entre ellos se encuentra el hecho de que la demografía se ha modificado; la esperanza de vida de las personas ha presentado un incremento considerable en las últimas décadas. En México la esperanza de vida de 1930 era de 34 años, en 2019 fue de 75 años (INEGI, 2021). Una consecuencia lógica de dicha modificación es que los esquemas de reparto en materia de pensiones han tenido que modificarse, en ocasiones de manera repentina y hasta agresiva. Por otra parte, al aumentar la esperanza de vida y las condiciones cambiantes del mercado, también han disminuido los empleos de por vida, provocando con ello una menor densidad de cotización. Finalmente, estos factores, al crear condiciones insostenibles en esquemas tradicionales de pensiones (Damián, 2016), han creado la necesidad de que el individuo tenga una responsabilidad y participación activa en la conformación de su fondo para el retiro.

La llegada de dicha crisis pensionaria ha sido motivo de preocupación tal, que se ha buscado darle solución al problema desde diferentes ámbitos (Ulloa, 2017). La
Asociación Mexicana de Actuarios Consultores (2018), por ejemplo, ofrece una serie de soluciones que incluyen crear un instituto especializado y reformar la ley para facilitar su operación. Ramírez, Rosado y Domínguez (2018) realizan un análisis donde se ilustra cómo la perspectiva de sostenibilidad del sistema de pensiones desde el punto de vista financiero es incierta si no se aborda un cambio. La OCDE (2015) incluso afirma que el nuevo sistema de pensiones sólo tendrá verdadero éxito si se incrementan las contribuciones obligatorias, un cambio significativo que ya se abordó en la reforma de 2020 a la Ley del Seguro Social.

\subsection{Cálculos actuales de CONSAR}

A causa de la reforma de la Ley del Seguro Social que se promulgó el día 16 de diciembre de 2020, los simuladores de la CONSAR no están disponibles y así será hasta nuevo aviso. El presente trabajo presenta una propuesta de cálculo de un fondo de pensiones considerando los cambios de dicha reforma.

\section{MÉTODO}

Para la presente investigación se utiliza el método de estudio de caso, por medio del cual se propone un escenario dado para un mexicano promedio y se analizan los escenarios a los que se enfrenta y las implicaciones que la educación financiera tendrá en ellos.

Los números presentados reflejan el impacto económico y social que la educación financiera básica tienen en el futuro de un mexicano cuyo salario mensual es de $\$ 7,640$, situación que comparte el $57.8 \%$ de la población en México de acuerdo a INEGI (2020) lo cual representa a la mayoría de la población. De acuerdo con estudios realizados por el Consejo Nacional de Evaluación de la Política de Desarrollo Social (2020), el costo mensual de la canasta alimentaria más la no alimentaria es de $\$ 3,295.73$ en la zona urbana, es decir el $43.14 \%$ del salario promedio de un mexicano. Esto es especialmente importante porque da una pauta para estimar la tasa de reemplazo mínima que una persona debería 
tener en su pensión para no caer en una situación de pobreza.

\section{RESULTADOS}

Se considera la situación de un mexicano que inicia labores el día 01 de enero de 2020. Considerando un salario mensual de $\$ 7,640$, un aumento del $1.5 \%$ anual, un ahorro obligatorio del $6.5 \%$ para afore entre $2020 \mathrm{y}$ 2022, con los respectivos aumentos en dicho porcentaje de conformidad con la modificación del artículo 168 de la ley del Seguro Social, un rendimiento promedio en afore del $4 \%$ anual y una comisión del $1.16 \%$, además de una vida laboral de 40 años con una densidad de cotización del $100 \%$, en contraposición con los datos de INEGI (2017) y de que algunos autores como Castañón y Ferreira (2017) afirman que la densidad de cotización requerida es de por lo menos el $60 \%$. Finalmente, para el cálculo se considera una esperanza de vida de 20 años tras la jubilación. Se obtiene que un mexicano promedio habrá ahorrado \$1'132,303.09. (véase anexo 1). De acuerdo a las regulaciones vigentes en materia de pensión, y como se aprecia en la tabla 1, dicho ahorro le proporcionará una pensión mensual de $\$ 6,796.69$ lo cual le permitiría obtener una tasa de reemplazo del $49.78 \%$ y que como se ha mencionado anteriormente, permitirá apenas que no se caiga en una situación de pobreza.

Tabla 1. Perspectiva en la jubilación para un mexicano promedio que inicia vida laboral en enero de 2020 y la concluye en diciembre de 2059

\begin{tabular}{|l|l|}
\hline Salario mensual inicial del trabajador & $\$ 7,640.00$ \\
\hline Aumento salarial del trabajador (anual) & $1.5 \%$ \\
\hline $\begin{array}{l}\text { Porcentaje que ahorra el trabajador para } \\
\text { su pensión }\end{array}$ & $\begin{array}{l}\text { 6.50\% de 2020 a } \\
\text { progresivamente } \\
\text { a para llegar } \\
2030\end{array}$ \\
\hline $\begin{array}{l}\text { Rendimiento de su fondo para el retiro } \\
\text { antes de jubilarse (anual) }\end{array}$ & $4 \%$ \\
\hline Comisión (anual) & $1.16 \%$ \\
\hline Esperanza de vida en años & 20 \\
\hline Fondo de ahorro para el retiro estimado & $\$ 1$ '132,303.09 \\
\hline Pensión mensual estimada & $\$ 6,796.69$ \\
\hline Tasa de reemplazo & $49.78 \%$ \\
\hline Fun
\end{tabular}

Fuente: Elaboración propia con datos de CONSAR (2019) y Ley de Seguro Social (2021)
Como se puede apreciar, la pensión de un mexicano promedio, equivalente al $49.78 \%$ de su último salario, alcanzará apenas a proveerle con los suficientes recursos para no caer en una situación de pobreza y para impedir que el Estado deba proporcionarle la pensión mínima que marca en su artículo 170 la Ley del Seguro Social (2020).

Dicha perspectiva, si bien tolerable, puede ser mejorada con la implementación de una estrategia financiera que se apoye en conocimientos financieros básicos. Para ello se considera, interpolando los datos ofrecidos por INFONAVIT (2019), que un mexicano que gana $\$ 7,640$ al mes adquirirá en promedio una vivienda de $\$ 357,774$ y pagará por ella una tasa de interés del $10.08 \%$ anual. Con un plazo de crédito de 30 años, los pagos mensuales que deberá realizar para dicho crédito son de $\$ 3,045.56$. Para efectos de estos cálculos y de acuerdo con el sistema de requisitos implementado por INFONAVIT (2021), se considera que la adquisición de la vivienda ocurrirá en el tercer año laboral de este mexicano promedio. Con esto en mente, se considerará que dicho mexicano promedio, gracias a una educación financiera básica, conoce las implicaciones que el interés compuesto tiene en su crédito Infonavit y se plantea invertir $\$ 200$ pesos mensuales (el $2.6 \%$ de sus ingresos) para abonar al capital de su crédito. La consecuencia es que este mexicano promedio habrá liquidado su crédito Infonavit 88 meses antes del plazo original y se habrá ahorrado $\$ 216,603.18$ por concepto de intereses. Si nuevamente producto de una educación financiera básica, destina dicho dinero a contribuir voluntariamente a su fondo de ahorro para el retiro, la consecuencia es que este mexicano promedio ahora cuenta con un ahorro acumulado de \$1'493,293.61 (véase anexo 2), mismo que le permitirá contar una pensión de $\$ 8,963.55$. Esta estrategia financiera le permitiría obtener una tasa de reemplazo de $65.65 \%$, así como un aumento en su pensión del $31.88 \%$ en comparación 
con la perspectiva actual que tiene, tal como se muestra en la tabla 2.

Tabla 2. Perspectiva en la jubilación para un mexicano promedio que inicia vida laboral en enero de 2020 y la concluye en diciembre de 2059, incluyendo estrategia financiera apoyada en una educación financiera básica

\begin{tabular}{|l|l|}
\hline Salario mensual inicial del trabajador & $\$ 7,640.00$ \\
\hline Aumento salarial del trabajador (anual) & $1.5 \%$ \\
\hline $\begin{array}{l}\text { Porcentaje que ahorra el trabajador para } \\
\text { su pensión }\end{array}$ & $\begin{array}{l}\text { 2022 para llegar } \\
\text { progresivamente } \\
\text { a 12.03\% en } \\
2030\end{array}$ \\
\hline $\begin{array}{l}\text { Rendimiento de su fondo para el retiro } \\
\text { antes de jubilarse (anual) }\end{array}$ & $4 \%$ \\
\hline Comisión (anual) & $1.16 \%$ \\
\hline Esperanza de vida en años & 20 \\
\hline Fondo de ahorro para el retiro estimado & $\$ 1$ '493,293.61 \\
\hline Pensión mensual estimada & $\$ 8,963.55$ \\
\hline Tasa de reemplazo & $65.65 \%$ \\
\hline $\begin{array}{l}\text { Fuente: Elaboración propia con datos de CONSAR (2019) y Ley } \\
\text { de Seguro Social (2021) }\end{array}$
\end{tabular}

Adicionalmente, considerando que según la Ley del Impuesto Sobre la Renta (2021), en su artículo 151, fracción V, un asalariado puede deducir las aportaciones que realiza a su fondo de ahorro para retiro que sean equivalentes hasta el $10 \%$ de sus ingresos, con el escenario planteado el asalariado también contaría con un saldo a favor por las aportaciones voluntarias que realiza, tal como se ilustra en la tabla 3.

Tabla 3. Ahorro fiscal para un mexicano promedio que inicia vida laboral en enero de

2020 y la concluye en diciembre de 2059, considerando una estrategia financiera apoyada en una educación financiera básica

\begin{tabular}{|c|c|c|c|c|}
\hline Año & $\begin{array}{c}\text { Salario } \\
\text { anual }\end{array}$ & Deducción & $\begin{array}{c}\text { \% sobre } \\
\text { excedente } \\
\text { de límite } \\
\text { superior }\end{array}$ & $\begin{array}{c}\text { Ahorro } \\
\text { fiscal }\end{array}$ \\
\hline 26 & $\$ 133,022.67$ & $\$ 12,182.24$ & $16.00 \%$ & $\$ 1,949.16$ \\
\hline 27 & $\$ 135,018.01$ & $\$ 13,501.80$ & $17.92 \%$ & $\$ 2,419.52$ \\
\hline 28 & $\$ 137,043.28$ & $\$ 13,704.33$ & $17.92 \%$ & $\$ 2,455.82$ \\
\hline 29 & $\$ 139,098.93$ & $\$ 13,909.89$ & $17.92 \%$ & $\$ 2,492.65$ \\
\hline 30 & $\$ 141,185.41$ & $\$ 14,118.54$ & $17.92 \%$ & $\$ 2,530.04$ \\
\hline 31 & $\$ 143,303.19$ & $\$ 14,330.32$ & $17.92 \%$ & $\$ 2,567.99$ \\
\hline 32 & $\$ 145,452.74$ & $\$ 14,545.27$ & $17.92 \%$ & $\$ 2,606.51$ \\
\hline
\end{tabular}

\begin{tabular}{|l|l|l|l|l|}
\hline 33 & $\$ 147,634.53$ & $\$ 14,763.45$ & $17.92 \%$ & $\$ 2,645.61$ \\
\hline & & & TOTAL & $\$ 19,667.31$ \\
\hline
\end{tabular}

Fuente: Elaboración propia con datos de Ley del Impuesto Sobre la Renta (2021)

Cabe mencionar que los costos asociados a este escenario representan una inversión nominal por parte del trabajador de $\$ 54,000$ pesos, un contraste interesante con los \$520,046.40 que recibirá como excedente, gracias a la aplicación de esta estrategia financiera básica para la obtención de su nueva pensión. Si se visualiza este dato cual, si fuera un proyecto de inversión y considerando una tasa de actualización, se determina que obtendría un rendimiento muy atractivo sobre su estrategia financiera, tal como se ilustra en la tabla 4.

Tabla 4. Proyecto de inversión

\begin{tabular}{|l|l|}
\hline Inversión requerida & $\$ 54,000.00$ \\
\hline Flujos del proyecto & $\$ 2,166.86$ \\
\hline Tasa anual & $4 \%$ \\
\hline Valor Presente Neto & $\$ 305,812.59$ \\
\hline Tasa Interna de Retorno (anualizada) & $60.33 \%$ \\
\hline Rendimiento sobre Inversión & $863.05 \%$ \\
\hline
\end{tabular}

Fuente: Elaboración propia con datos del caso de estudio

Con base en estos resultados, se puede observar que es una inversión atractiva desde el punto de vista del individuo, pero también es una inversión atractiva desde el punto de vista del Estado. Si bien el costo asociado de poner en práctica esta estrategia corre a cuenta del individuo, el costo de sensibilizarlos para que conozcan dicha opción es de la sociedad. Desde luego, habría que realizar estudios posteriores que reflejen los costos asociados a promover una mejor educación financiera, además de considerar las implicaciones que tendría para el INFONAVIT, la puesta en marcha de una estrategia financiera de esta naturaleza, por un porcentaje importante de sus derechohabientes. En dicho estudio deben consultarse las perspectivas que para tal efecto ofrezcan el Estado, el INFONAVIT, la CONSAR y toda institución involucrada.

\section{CONCLUSIONES}

Una educación financiera básica tiene un impacto significativo en el futuro 
financiero de un individuo y también en el de las finanzas públicas del país en el que habita. En un mundo donde se ha vuelto especialmente importante eficientar $y$ maximizar los recursos, se vuelve vital hacer partícipes de las mejoras a la población general si es que se pretende avanzar como sociedad hacia un escenario idóneo.

La crisis de pensiones es inminente, y se observa que actualmente se están buscando soluciones desde el punto de vista social, fiscal, económico, integral; el presente artículo pretende ofrecer una solución desde el punto de vista de la educación financiera y su papel como un motor para el cambio de hábitos y actitudes entre la población mexicana. Mucho se ha hablado de la necesidad de fortalecer y garantizar las aportaciones voluntarias al fondo de pensión entre la población mexicana, pero para que se dé dicho cambio debe haber una fuerza impulsora que ilustre y convenza a la población de su verdadera utilidad y es ahí donde la educación financiera tiene su papel. En el presente trabajo se ha expuesto el gran impacto que una sola decisión financiera puede tener en el futuro de un individuo para mejorar su calidad de vida y para aligerar la carga del Estado. Además, este tipo de estrategias brindan una alternativa de solución a la inminente crisis de pensiones en México. La educación siempre ha sido un motor potente de desarrollo y evolución para la sociedad y en este aspecto la educación financiera puede tener un mayor realce, pues se observa que tiene el potencial para retribuir un bienestar mucho mayor que la inversión que se hará para impartirla. 


\section{REFERENCIAS}

Asociación Mexicana de Actuarios Consultores (2018). Propuesta para resolver la problemática de las pensiones en México. México: AMAC.

Banco del Bienestar, Sociedad Nacional de Crédito, Institución de Banca de Desarrollo (2019). Educación financiera. México: Bansefi. Recuperado de: https://www.gob.mx/bancodelbienestar/documentos/bansefi-y-la-educacion-financiera

Carrillo, C. y J. Lamamié (2008). Educación financiera y ahorro familiar. Implicaciones de la crisis financiera global. file:///D:/usuario/Downloads/13-1301393911CUADERNO391184_163.pdf

Castañón, V., y Ferreira, O. F. (2017). Densidades de cotización en el sistema de ahorro para el retiro en México (documento de trabajo 3). México: Consar.

Consejo Nacional de Evaluación de la Política de Desarrollo Social (2020). Evolución de las líneas de pobreza por ingresos. En https://www.coneval.org.mx/Medicion/MP/Paginas/Lineas-dePobreza-por-Ingresos.aspx

Damián, A. (2016). Seguridad social, pensiones y pobreza de los adultos mayores en México. Acta Sociológica, 70 ,

$151-172$.

En http://www.revistas.unam.mx/index.php/ras/article/view/57839/51247

Instituto del Fondo Nacional de la Vivienda para los Trabajadores (2019). Reporte anual de vivienda 2019 Infonavit. En https://portalmx.infonavit.org.mx/wps/wcm/connect/6a22332f-f9fe-4f17$8 \mathrm{~d} 93-$

9efc959086b2/ReporteAnualVivienda2019.pdf?MOD=AJPERES\&CVID=mW5tCKM

Instituto del Fondo Nacional de la Vivienda para los Trabajadores (2019). Precalificación. En https://precalificaciones.infonavit.org.mx/Precalificacion/resources/pdf/TABLAS_DE_CA LCULO_DE_PUNTUACION.pdf

Instituto Nacional de Estadística y Geografía (2021). Esperanza de vida. En http://cuentame.inegi.org.mx/poblacion/esperanza.aspx?tema=P

Instituto Nacional de Estadística y Geografía (2017). Encuesta Nacional de Empleo y Seguridad Social (ENESS) 2017. México: En https://www.inegi.org.mx/programas/eness/2017/

Instituto Nacional de Estadística y Geografía (2018). Encuesta Nacional de Inclusión Financiera. México: INEGI. En https://www.inegi.org.mx/programas/enif/2018/

$\begin{array}{llllll}\text { Ley del Impuesto } & \text { Sobre la } & \text { Renta }\end{array}$ http://www.diputados.gob.mx/LeyesBiblio/pdf/LISR_230421.pdf

$\begin{array}{lllll}\text { Ley } & \text { del } & \text { Seguro } & \text { Social } & \text { (2020). }\end{array}$ http://www.ordenjuridico.gob.mx/Documentos/Federal/html/wo9056.html

Moreno-García, E., García-Santillán, A. y Gutiérrez-Delgado, L. (2017). Nivel de educación financiera en escenarios de educación superior. Revista Iberoamericana de Educación Superior, VIII (22), 163-183.

OCDE (2015). Estudio de la OCDE sobre los sistemas de pensiones. México: OCDE/Consar.

Ramírez, B. (2019). La necesaria construcción de un sistema público de pensiones para la sociedad mexicana. El Trimestre Económico, 86(344), 967. https://doi.org/10.20430/ete.v86i344.982

Ramírez, B., Rosado, B., y Domínguez, I. (2018). Influencia del mercado de trabajo en las pensiones de México y España a partir de la tasa interna de rendimiento. Revista Mexicana de Economía y Finanzas, 13(1), 99-131.

Ramírez Fuentes, C. (2017). Reforma de pensiones en México: avances, logros y retos. El Cotidiano, 204, 29-39. http://www.redalyc.org/articulo.oa?id=32553151003

Ulloa, O. (2017). Reforma de pensiones en México: diseño, promesas y evidencias. El Cotidiano, 204, 7-28.

Zakaria, R., Jaafar, N. y Marican, S. (2012). Financial behavior and financial position: a structural equation modelling approach. Middle-East Journal of Scientific Research, 12(10), 13961402 . 
ANEXO 1. Tabla de fondo de ahorro para el retiro, correspondiente a perspectiva de jubilación de un mexicano promedio, sin contar con una estrategia financiera

\begin{tabular}{|c|c|c|c|c|c|c|c|c|c|}
\hline Periodo & Salario mensual & & $\begin{array}{l}\text { Obligatorio } \\
\text { (Ao) }\end{array}$ & $\begin{array}{c}\text { Ahorro voluntario } \\
\text { (Av) }\end{array}$ & \multicolumn{2}{|c|}{$\begin{array}{c}\text { Cuota social } \\
\text { (Cs) }\end{array}$} & Rendimiento neto & \multicolumn{2}{|c|}{$\begin{array}{l}\text { Fondo de ahorro para } \\
\text { el retiro acumulado }\end{array}$} \\
\hline Mes 309 & $\$ 11,085.22$ & $\$$ & $1,333.22$ & & $\$$ & 232.50 & $\$ 1,199.64$ & $\$$ & $521,184.11$ \\
\hline Mes 310 & $\$ 11,085.22$ & $\$$ & $1,333.22$ & & $\$$ & 232.50 & $\$ 1,206.02$ & $\$$ & $523,955.85$ \\
\hline Mes 311 & $\$ 11,085.22$ & $\$$ & $1,333.22$ & & $\$$ & 232.50 & $\$ 1,212.42$ & $\$$ & $526,733.99$ \\
\hline Mes 312 & $\$ 11,085.22$ & $\$$ & $1,333.22$ & & $\$$ & 232.50 & $\$ 1,218.83$ & $\$$ & $529,518.54$ \\
\hline Mes 313 & $\$ 11,251.50$ & $\$$ & $1,353.22$ & & $\$$ & 232.50 & $\$ 1,225.30$ & $\$$ & $532,329.55$ \\
\hline Mes 314 & $\$ 11,251.50$ & $\$$ & $1,353.22$ & & $\$$ & 232.50 & $\$ 1,231.78$ & $\$$ & $535,147.05$ \\
\hline Mes 315 & $\$ 11,251.50$ & $\$$ & $1,353.22$ & & $\$$ & 232.50 & $\$ 1,238.28$ & $\$$ & $537,971.05$ \\
\hline Mes 316 & $\$ 11,251.50$ & $\$$ & $1,353.22$ & & $\$$ & 232.50 & $\$ 1,244.80$ & $\$$ & $540,801.56$ \\
\hline Mes 317 & $\$ 11,251.50$ & $\$$ & $1,353.22$ & & $\$$ & 232.50 & $\$ 1,251.33$ & $\$$ & $543,638.61$ \\
\hline Mes 318 & $\$ 11,251.50$ & $\$$ & $1,353.22$ & & $\$$ & 232.50 & $\$ 1,257.87$ & $\$$ & $546,482.20$ \\
\hline Mes 319 & $\$ 11,251.50$ & $\$$ & $1,353.22$ & & $\$$ & 232.50 & $\$ 1,264.43$ & $\$$ & $549,332.35$ \\
\hline Mes 320 & $\$ 11,251.50$ & $\$$ & $1,353.22$ & & $\$$ & 232.50 & $\$ 1,271.01$ & $\$$ & $552,189.08$ \\
\hline Mes 321 & $\$ 11,251.50$ & $\$$ & $1,353.22$ & & $\$$ & 232.50 & $\$ 1,277.60$ & $\$$ & $555,052.39$ \\
\hline Mes 322 & $\$ 11,251.50$ & $\$$ & $1,353.22$ & & $\$$ & 232.50 & $\$ 1,284.20$ & $\$$ & $557,922.32$ \\
\hline Mes 323 & $\$ 11,251.50$ & $\$$ & $1,353.22$ & & $\$$ & 232.50 & $\$ 1,290.83$ & $\$$ & $560,798.86$ \\
\hline Mes 324 & $\$ 11,251.50$ & $\$$ & $1,353.22$ & & $\$$ & 232.50 & $\$ 1,297.46$ & $\$$ & $563,682.04$ \\
\hline Mes 325 & $\$ 11,420.27$ & $\$$ & $1,373.52$ & & $\$$ & 232.50 & $\$ 1,304.16$ & $\$$ & $566,592.22$ \\
\hline Mes 326 & $\$ 11,420.27$ & $\$$ & $1,373.52$ & & $\$$ & 232.50 & $\$ 1,310.87$ & $\$$ & $569,509.11$ \\
\hline Mes 327 & $\$ 11,420.27$ & $\$$ & $1,373.52$ & & $\$$ & 232.50 & $\$ 1,317.60$ & $\$$ & $572,432.73$ \\
\hline Mes 328 & $\$ 11,420.27$ & $\$$ & $1,373.52$ & & $\$$ & 232.50 & $\$ 1,324.35$ & $\$$ & $575,363.10$ \\
\hline Mes 329 & $\$ 11,420.27$ & $\$$ & $1,373.52$ & & $\$$ & 232.50 & $\$ 1,331.11$ & $\$$ & $578,300.22$ \\
\hline Mes 330 & $\$ 11,420.27$ & $\$$ & $1,373.52$ & & $\$$ & 232.50 & $\$ 1,337.89$ & $\$$ & $581,244.12$ \\
\hline Mes 331 & $\$ 11,420.27$ & $\$$ & $1,373.52$ & & $\$$ & 232.50 & $\$ 1,344.68$ & $\$$ & $584,194.82$ \\
\hline Mes 332 & $\$ 11,420.27$ & $\$$ & $1,373.52$ & & $\$$ & 232.50 & $\$ 1,351.49$ & $\$$ & $587,152.32$ \\
\hline Mes 333 & $\$ 11,420.27$ & $\$$ & $1,373.52$ & & $\$$ & 232.50 & $\$ 1,358.31$ & $\$$ & $590,116.64$ \\
\hline Mes 334 & $\$ 11,420.27$ & $\$$ & $1,373.52$ & & $\$$ & 232.50 & $\$ 1,365.15$ & $\$$ & $593,087.81$ \\
\hline Mes 335 & $\$ 11,420.27$ & $\$$ & $1,373.52$ & & $\$$ & 232.50 & $\$ 1,372.00$ & $\$$ & $596,065.83$ \\
\hline Mes 336 & $\$ 11,420.27$ & $\$$ & $1,373.52$ & & $\$$ & 232.50 & $\$ 1,378.87$ & $\$$ & $599,050.72$ \\
\hline Mes 337 & $\$ 11,591.58$ & $\$$ & $1,394.12$ & & $\$$ & 232.50 & $\$ 1,385.81$ & $\$$ & $602,063.14$ \\
\hline Mes 338 & $\$ 11,591.58$ & $\$$ & $1,394.12$ & & $\$$ & 232.50 & $\$ 1,392.76$ & $\$$ & $605,082.52$ \\
\hline Mes 339 & $\$ 11,591.58$ & $\$$ & $1,394.12$ & & $\$$ & 232.50 & $\$ 1,399.72$ & $\$$ & $608,108.86$ \\
\hline Mes 340 & $\$ 11,591.58$ & $\$$ & $1,394.12$ & & $\$$ & 232.50 & $\$ 1,406.70$ & $\$$ & $611,142.18$ \\
\hline Mes 341 & $\$ 11,591.58$ & $\$$ & $1,394.12$ & & $\$$ & 232.50 & $\$ 1,413.70$ & $\$$ & $614,182.50$ \\
\hline Mes 342 & $\$ 11,591.58$ & $\$$ & $1,394.12$ & & $\$$ & 232.50 & $\$ 1,420.72$ & $\$$ & $617,229.84$ \\
\hline Mes 343 & $\$ 11,591.58$ & $\$$ & $1,394.12$ & & $\$$ & 232.50 & $\$ 1,427.75$ & $\$$ & $620,284.20$ \\
\hline Mes 344 & $\$ 11,591.58$ & $\$$ & $1,394.12$ & & $\$$ & 232.50 & $\$ 1,434.79$ & $\$$ & $623,345.62$ \\
\hline Mes 345 & $\$ 11,591.58$ & $\$$ & $1,394.12$ & & $\$$ & 232.50 & $\$ 1,441.86$ & $\$$ & $626,414.09$ \\
\hline
\end{tabular}




\begin{tabular}{|c|c|c|c|c|c|c|c|c|}
\hline Mes 346 & $\$ 11,591.58$ & $\$$ & $1,394.12$ & $\$$ & 232.50 & $\$ 1,448.94$ & $\$$ & $629,489.65$ \\
\hline Mes 347 & $\$ 11,591.58$ & $\$$ & $1,394.12$ & $\$$ & 232.50 & $\$ 1,456.03$ & $\$$ & $632,572.30$ \\
\hline Mes 348 & $\$ 11,591.58$ & $\$$ & $1,394.12$ & $\$$ & 232.50 & $\$ 1,463.14$ & $\$$ & $635,662.06$ \\
\hline Mes 349 & $\$ 11,765.45$ & $\$$ & $1,415.03$ & $\$$ & 232.50 & $\$ 1,470.32$ & $\$$ & $638,779.91$ \\
\hline Mes 350 & $\$ 11,765.45$ & $\$$ & $1,415.03$ & $\$$ & 232.50 & $\$ 1,477.51$ & $\$$ & $641,904.96$ \\
\hline Mes 351 & $\$ 11,765.45$ & $\$$ & $1,415.03$ & $\$$ & 232.50 & $\$ 1,484.72$ & $\$$ & $645,037.21$ \\
\hline Mes 352 & $\$ 11,765.45$ & $\$$ & $1,415.03$ & $\$$ & 232.50 & $\$ 1,491.95$ & $\$$ & $648,176.69$ \\
\hline Mes 353 & $\$ 11,765.45$ & $\$$ & $1,415.03$ & $\$$ & 232.50 & $\$ 1,499.19$ & $\$$ & $651,323.41$ \\
\hline Mes 354 & $\$ 11,765.45$ & $\$$ & $1,415.03$ & $\$$ & 232.50 & $\$ 1,506.45$ & $\$$ & $654,477.39$ \\
\hline Mes 355 & $\$ 11,765.45$ & $\$$ & $1,415.03$ & $\$$ & 232.50 & $\$ 1,513.73$ & $\$$ & $657,638.65$ \\
\hline Mes 356 & $\$ 11,765.45$ & $\$$ & $1,415.03$ & $\$$ & 232.50 & $\$ 1,521.02$ & $\$$ & $660,807.21$ \\
\hline Mes 357 & $\$ 11,765.45$ & $\$$ & $1,415.03$ & $\$$ & 232.50 & $\$ 1,528.33$ & $\$$ & $663,983.07$ \\
\hline Mes 358 & $\$ 11,765.45$ & $\$$ & $1,415.03$ & $\$$ & 232.50 & $\$ 1,535.66$ & $\$$ & $667,166.26$ \\
\hline Mes 359 & $\$ 11,765.45$ & $\$$ & $1,415.03$ & $\$$ & 232.50 & $\$ 1,543.00$ & $\$$ & $670,356.79$ \\
\hline Mes 360 & $\$ 11,765.45$ & $\$$ & $1,415.03$ & $\$$ & 232.50 & $\$ 1,550.36$ & $\$$ & $673,554.68$ \\
\hline Mes 361 & $\$ 11,941.93$ & $\$$ & $1,436.26$ & $\$$ & 232.50 & $\$ 1,557.79$ & $\$$ & $676,781.23$ \\
\hline Mes 362 & $\$ 11,941.93$ & $\$$ & $1,436.26$ & $\$$ & 232.50 & $\$ 1,565.23$ & $\$$ & $680,015.22$ \\
\hline Mes 363 & $\$ 11,941.93$ & $\$$ & $1,436.26$ & $\$$ & 232.50 & $\$ 1,572.69$ & $\$$ & $683,256.67$ \\
\hline Mes 364 & $\$ 11,941.93$ & $\$$ & $1,436.26$ & $\$$ & 232.50 & $\$ 1,580.17$ & $\$$ & $686,505.60$ \\
\hline Mes 365 & $\$ 11,941.93$ & $\$$ & $1,436.26$ & $\$$ & 232.50 & $\$ 1,587.67$ & $\$$ & $689,762.02$ \\
\hline Mes 366 & $\$ 11,941.93$ & $\$$ & $1,436.26$ & $\$$ & 232.50 & $\$ 1,595.18$ & $\$$ & $693,025.96$ \\
\hline Mes 367 & $\$ 11,941.93$ & $\$$ & $1,436.26$ & $\$$ & 232.50 & $\$ 1,602.71$ & $\$$ & $696,297.43$ \\
\hline Mes 368 & $\$ 11,941.93$ & $\$$ & $1,436.26$ & $\$$ & 232.50 & $\$ 1,610.26$ & $\$$ & $699,576.45$ \\
\hline Mes 369 & $\$ 11,941.93$ & $\$$ & $1,436.26$ & $\$$ & 232.50 & $\$ 1,617.82$ & $\$$ & $702,863.03$ \\
\hline Mes 370 & $\$ 11,941.93$ & $\$$ & $1,436.26$ & $\$$ & 232.50 & $\$ 1,625.41$ & $\$$ & $706,157.19$ \\
\hline Mes 371 & $\$ 11,941.93$ & $\$$ & $1,436.26$ & $\$$ & 232.50 & $\$ 1,633.01$ & $\$$ & $709,458.95$ \\
\hline Mes 372 & $\$ 11,941.93$ & $\$$ & $1,436.26$ & $\$$ & 232.50 & $\$ 1,640.62$ & $\$$ & $712,768.33$ \\
\hline Mes 373 & $\$ 12,121.06$ & $\$$ & $1,457.80$ & $\$$ & 232.50 & $\$ 1,648.31$ & $\$$ & $716,106.94$ \\
\hline Mes 374 & $\$ 12,121.06$ & $\$$ & $1,457.80$ & $\$$ & 232.50 & $\$ 1,656.01$ & $\$$ & $719,453.25$ \\
\hline Mes 375 & $\$ 12,121.06$ & $\$$ & $1,457.80$ & $\$$ & 232.50 & $\$ 1,663.73$ & $\$$ & $722,807.28$ \\
\hline Mes 376 & $\$ 12,121.06$ & $\$$ & $1,457.80$ & $\$$ & 232.50 & $\$ 1,671.47$ & $\$$ & $726,169.05$ \\
\hline Mes 377 & $\$ 12,121.06$ & $\$$ & $1,457.80$ & $\$$ & 232.50 & $\$ 1,679.22$ & $\$$ & $729,538.57$ \\
\hline Mes 378 & $\$ 12,121.06$ & $\$$ & $1,457.80$ & $\$$ & 232.50 & $\$ 1,687.00$ & $\$$ & $732,915.87$ \\
\hline Mes 379 & $\$ 12,121.06$ & $\$$ & $1,457.80$ & $\$$ & 232.50 & $\$ 1,694.79$ & $\$$ & $736,300.96$ \\
\hline Mes 380 & $\$ 12,121.06$ & $\$$ & $1,457.80$ & $\$$ & 232.50 & $\$ 1,702.60$ & $\$$ & $739,693.86$ \\
\hline Mes 381 & $\$ 12,121.06$ & $\$$ & $1,457.80$ & $\$$ & 232.50 & $\$ 1,710.43$ & $\$$ & $743,094.59$ \\
\hline Mes 382 & $\$ 12,121.06$ & $\$$ & $1,457.80$ & $\$$ & 232.50 & $\$ 1,718.27$ & $\$$ & $746,503.16$ \\
\hline Mes 383 & $\$ 12,121.06$ & $\$$ & $1,457.80$ & $\$$ & 232.50 & $\$ 1,726.14$ & $\$$ & $749,919.60$ \\
\hline Mes 384 & $\$ 12,121.06$ & $\$$ & $1,457.80$ & $\$$ & 232.50 & $\$ 1,734.02$ & $\$$ & $753,343.92$ \\
\hline Mes 385 & $\$ 12,302.88$ & $\$$ & $1,479.67$ & $\$$ & 232.50 & $\$ 1,741.97$ & $\$$ & $756,798.06$ \\
\hline Mes 386 & $\$ 12,302.88$ & $\$$ & $1,479.67$ & $\$$ & 232.50 & $\$ 1,749.94$ & $\$$ & $760,260.16$ \\
\hline
\end{tabular}




\begin{tabular}{|c|c|c|c|c|c|c|c|c|}
\hline Mes 387 & $\$ 12,302.88$ & $\$$ & $1,479.67$ & $\$$ & 232.50 & $\$ 1,757.93$ & $\$$ & $763,730.26$ \\
\hline Mes 388 & $\$ 12,302.88$ & $\$$ & $1,479.67$ & $\$$ & 232.50 & $\$ 1,765.93$ & $\$$ & $767,208.35$ \\
\hline Mes 389 & $\$ 12,302.88$ & $\$$ & $1,479.67$ & $\$$ & 232.50 & $\$ 1,773.96$ & $\$$ & $770,694.48$ \\
\hline Mes 390 & $\$ 12,302.88$ & $\$$ & $1,479.67$ & $\$$ & 232.50 & $\$ 1,782.00$ & $\$$ & $774,188.64$ \\
\hline Mes 391 & $\$ 12,302.88$ & $\$$ & $1,479.67$ & $\$$ & 232.50 & $\$ 1,790.06$ & $\$$ & $777,690.87$ \\
\hline Mes 392 & $\$ 12,302.88$ & $\$$ & $1,479.67$ & $\$$ & 232.50 & $\$ 1,798.14$ & $\$$ & $781,201.18$ \\
\hline Mes 393 & $\$ 12,302.88$ & $\$$ & $1,479.67$ & $\$$ & 232.50 & $\$ 1,806.24$ & $\$$ & $784,719.58$ \\
\hline Mes 394 & $\$ 12,302.88$ & $\$$ & $1,479.67$ & $\$$ & 232.50 & $\$ 1,814.36$ & $\$$ & $788,246.11$ \\
\hline Mes 395 & $\$ 12,302.88$ & $\$$ & $1,479.67$ & $\$$ & 232.50 & $\$ 1,822.49$ & $\$$ & $791,780.76$ \\
\hline Mes 396 & $\$ 12,302.88$ & $\$$ & $1,479.67$ & $\$$ & 232.50 & $\$ 1,830.65$ & $\$$ & $795,323.58$ \\
\hline Mes 397 & $\$ 12,487.42$ & $\$$ & $1,501.86$ & $\$$ & 232.50 & $\$ 1,838.87$ & $\$$ & $798,896.81$ \\
\hline Mes 398 & $\$ 12,487.42$ & $\$$ & $1,501.86$ & $\$$ & 232.50 & $\$ 1,847.11$ & $\$$ & $802,478.29$ \\
\hline Mes 399 & $\$ 12,487.42$ & $\$$ & $1,501.86$ & $\$$ & 232.50 & $\$ 1,855.38$ & $\$$ & $806,068.03$ \\
\hline Mes 400 & $\$ 12,487.42$ & $\$$ & $1,501.86$ & $\$$ & 232.50 & $\$ 1,863.66$ & $\$$ & $809,666.05$ \\
\hline Mes 401 & $\$ 12,487.42$ & $\$$ & $1,501.86$ & $\$$ & 232.50 & $\$ 1,871.96$ & $\$$ & $813,272.37$ \\
\hline Mes 402 & $\$ 12,487.42$ & $\$$ & $1,501.86$ & $\$$ & 232.50 & $\$ 1,880.28$ & $\$$ & $816,887.01$ \\
\hline Mes 403 & $\$ 12,487.42$ & $\$$ & $1,501.86$ & $\$$ & 232.50 & $\$ 1,888.62$ & $\$$ & $820,509.99$ \\
\hline Mes 404 & $\$ 12,487.42$ & $\$$ & $1,501.86$ & $\$$ & 232.50 & $\$ 1,896.98$ & $\$$ & $824,141.33$ \\
\hline Mes 405 & $\$ 12,487.42$ & $\$$ & $1,501.86$ & $\$$ & 232.50 & $\$ 1,905.36$ & $\$$ & $827,781.05$ \\
\hline Mes 406 & $\$ 12,487.42$ & $\$$ & $1,501.86$ & $\$$ & 232.50 & $\$ 1,913.75$ & $\$$ & $831,429.17$ \\
\hline Mes 407 & $\$ 12,487.42$ & $\$$ & $1,501.86$ & $\$$ & 232.50 & $\$ 1,922.17$ & $\$$ & $835,085.70$ \\
\hline Mes 408 & $\$ 12,487.42$ & $\$$ & $1,501.86$ & $\$$ & 232.50 & $\$ 1,930.61$ & $\$$ & $838,750.67$ \\
\hline Mes 409 & $\$ 12,674.73$ & $\$$ & $1,524.39$ & $\$$ & 232.50 & $\$ 1,939.11$ & $\$$ & $842,446.67$ \\
\hline Mes 410 & $\$ 12,674.73$ & $\$$ & $1,524.39$ & $\$$ & 232.50 & $\$ 1,947.64$ & $\$$ & $846,151.20$ \\
\hline Mes 411 & $\$ 12,674.73$ & $\$$ & $1,524.39$ & $\$$ & 232.50 & $\$ 1,956.19$ & $\$$ & $849,864.27$ \\
\hline Mes 412 & $\$ 12,674.73$ & $\$$ & $1,524.39$ & $\$$ & 232.50 & $\$ 1,964.75$ & $\$$ & $853,585.92$ \\
\hline Mes 413 & $\$ 12,674.73$ & $\$$ & $1,524.39$ & $\$$ & 232.50 & $\$ 1,973.34$ & $\$$ & $857,316.14$ \\
\hline Mes 414 & $\$ 12,674.73$ & $\$$ & $1,524.39$ & $\$$ & 232.50 & $\$ 1,981.94$ & $\$$ & $861,054.98$ \\
\hline Mes 415 & $\$ 12,674.73$ & $\$$ & $1,524.39$ & $\$$ & 232.50 & $\$ 1,990.57$ & $\$$ & $864,802.44$ \\
\hline Mes 416 & $\$ 12,674.73$ & $\$$ & $1,524.39$ & $\$$ & 232.50 & $\$ 1,999.22$ & $\$$ & $868,558.54$ \\
\hline Mes 417 & $\$ 12,674.73$ & $\$$ & $1,524.39$ & $\$$ & 232.50 & $\$ 2,007.88$ & $\$$ & $872,323.32$ \\
\hline Mes 418 & $\$ 12,674.73$ & $\$$ & $1,524.39$ & $\$$ & 232.50 & $\$ 2,016.57$ & $\$$ & $876,096.77$ \\
\hline Mes 419 & $\$ 12,674.73$ & $\$$ & $1,524.39$ & $\$$ & 232.50 & $\$ 2,025.27$ & $\$$ & $879,878.94$ \\
\hline Mes 420 & $\$ 12,674.73$ & $\$$ & $1,524.39$ & $\$$ & 232.50 & $\$ 2,034.00$ & $\$$ & $883,669.82$ \\
\hline Mes 421 & $\$ 12,864.85$ & $\$$ & $1,547.26$ & $\$$ & 232.50 & $\$ 2,042.80$ & $\$$ & $887,492.38$ \\
\hline Mes 422 & $\$ 12,864.85$ & $\$$ & $1,547.26$ & $\$$ & 232.50 & $\$ 2,051.62$ & $\$$ & $891,323.75$ \\
\hline Mes 423 & $\$ 12,864.85$ & $\$$ & $1,547.26$ & $\$$ & 232.50 & $\$ 2,060.46$ & $\$$ & $895,163.96$ \\
\hline Mes 424 & $\$ 12,864.85$ & $\$$ & $1,547.26$ & $\$$ & 232.50 & $\$ 2,069.31$ & $\$$ & $899,013.03$ \\
\hline Mes 425 & $\$ 12,864.85$ & $\$$ & $1,547.26$ & $\$$ & 232.50 & $\$ 2,078.19$ & $\$$ & $902,870.98$ \\
\hline Mes 426 & $\$ 12,864.85$ & $\$$ & $1,547.26$ & $\$$ & 232.50 & $\$ 2,087.10$ & $\$$ & $906,737.83$ \\
\hline Mes 427 & $\$ 12,864.85$ & $\$$ & $1,547.26$ & $\$$ & 232.50 & $\$ 2,096.02$ & $\$$ & $910,613.60$ \\
\hline
\end{tabular}




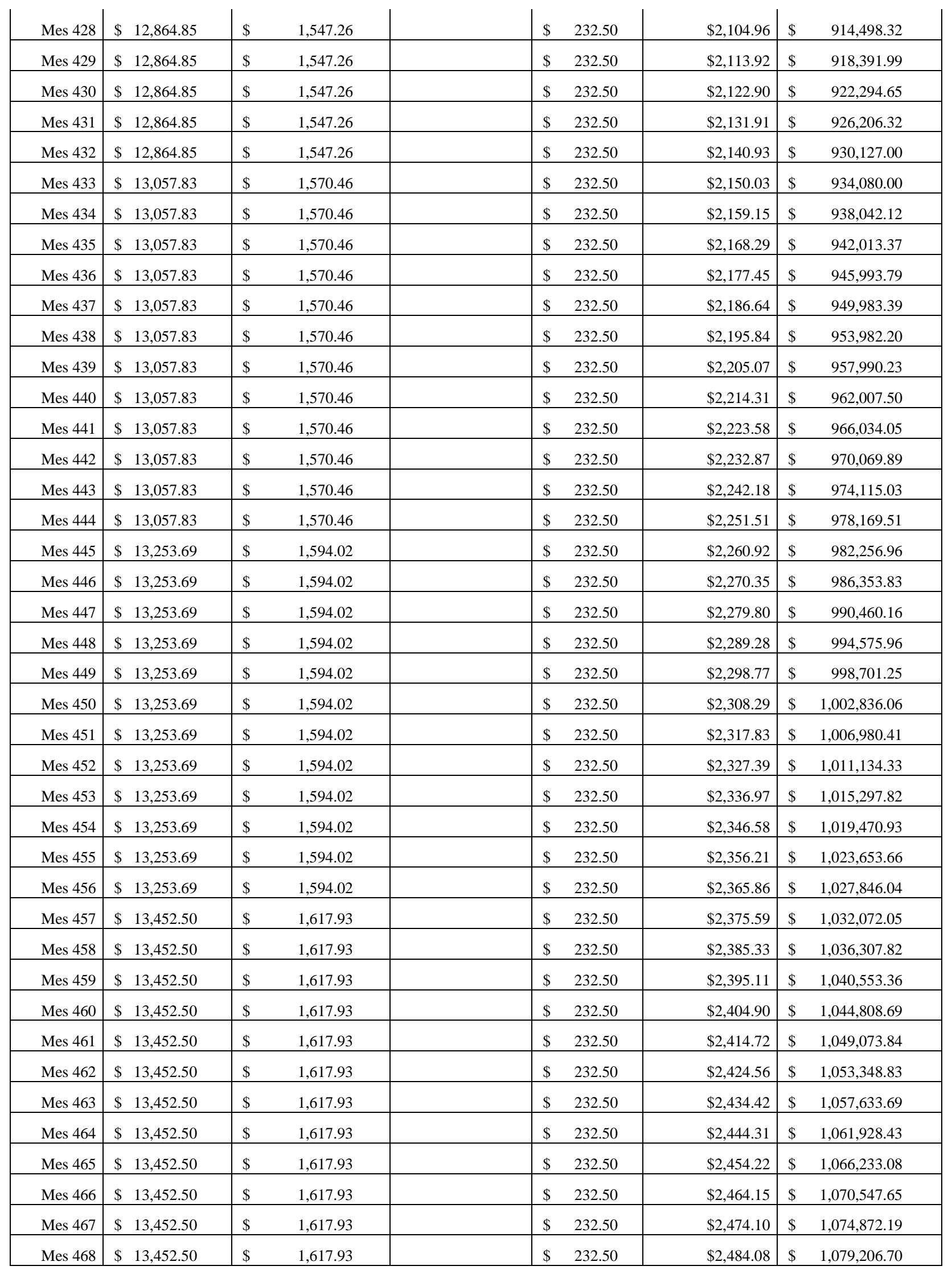




\begin{tabular}{|c|c|c|c|c|c|c|c|c|}
\hline Mes 469 & $\$ 13,654.29$ & $\$$ & $1,642.20$ & $\$$ & 232.50 & $\$ 2,494.13$ & $\$$ & $1,083,575.53$ \\
\hline Mes 470 & $\$ 13,654.29$ & $\$$ & $1,642.20$ & $\$$ & 232.50 & $\$ 2,504.21$ & $\$$ & $1,087,954.45$ \\
\hline Mes 471 & $\$ 13,654.29$ & $\$$ & $1,642.20$ & $\$$ & 232.50 & $\$ 2,514.32$ & $\$$ & $1,092,343.46$ \\
\hline Mes 472 & $\$ 13,654.29$ & $\$$ & $1,642.20$ & $\$$ & 232.50 & $\$ 2,524.44$ & $\$$ & $1,096,742.60$ \\
\hline Mes 473 & $\$ 13,654.29$ & $\$$ & $1,642.20$ & $\$$ & 232.50 & $\$ 2,534.59$ & $\$$ & $1,101,151.90$ \\
\hline Mes 474 & $\$ 13,654.29$ & $\$$ & $1,642.20$ & $\$$ & 232.50 & $\$ 2,544.76$ & $\$$ & $1,105,571.36$ \\
\hline Mes 475 & $\$ 13,654.29$ & $\$$ & $1,642.20$ & $\$$ & 232.50 & $\$ 2,554.96$ & $\$$ & $1,110,001.02$ \\
\hline Mes 476 & $\$ 13,654.29$ & $\$$ & $1,642.20$ & $\$$ & 232.50 & $\$ 2,565.18$ & $\$$ & $1,114,440.90$ \\
\hline Mes 477 & $\$ 13,654.29$ & $\$$ & $1,642.20$ & $\$$ & 232.50 & $\$ 2,575.42$ & $\$$ & $1,118,891.02$ \\
\hline Mes 478 & $\$ 13,654.29$ & $\$$ & $1,642.20$ & $\$$ & 232.50 & $\$ 2,585.69$ & $\$$ & $1,123,351.41$ \\
\hline Mes 479 & $\$ 13,654.29$ & $\$$ & $1,642.20$ & $\$$ & 232.50 & $\$ 2,595.98$ & $\$$ & $1,127,822.09$ \\
\hline Mes 480 & $\$ 13,654.29$ & $\$$ & $1,642.20$ & $\$$ & 232.50 & $\$ 2,606.29$ & $\$$ & $1,132,303.09$ \\
\hline
\end{tabular}

Fuente: Elaboración propia con datos de CONSAR (2019) y Ley de Seguro Social (2021)

ANEXO 2. Tabla de fondo de ahorro para el retiro, correspondiente a estrategia financiera basada en una educación financiera básica, a partir del inicio de las aportaciones voluntarias

\begin{tabular}{|c|c|c|c|c|c|c|c|c|c|c|}
\hline \multirow{2}{*}{$\begin{array}{l}\text { Periodo } \\
\text { Mes } 309\end{array}$} & Salario mensual & \multicolumn{2}{|c|}{$\begin{array}{c}\text { Ahorro Obligatorio } \\
\text { (Ao) }\end{array}$} & \multicolumn{2}{|c|}{$\begin{array}{c}\text { Ahorro voluntario } \\
\text { (Av) }\end{array}$} & \multicolumn{2}{|c|}{$\begin{array}{c}\text { Cuota social } \\
\text { (Cs) }\end{array}$} & \multirow{2}{*}{\begin{tabular}{|r} 
Rendimiento neto \\
$\$ 1,206.67$ \\
\end{tabular}} & \multicolumn{2}{|c|}{$\begin{array}{l}\text { Fondo de ahorro para el } \\
\text { retiro acumulado }\end{array}$} \\
\hline & $\$ 11,085.22$ & $\$$ & $1,333.22$ & $\$$ & $3,045.56$ & $\$$ & 232.50 & & $\$$ & $524,236.70$ \\
\hline Mes 310 & $\$ 11,085.22$ & $\$$ & $1,333.22$ & $\$$ & $3,045.56$ & $\$$ & 232.50 & $\$ 1,220.09$ & $\$$ & $530,068.07$ \\
\hline Mes 311 & $\$ 11,085.22$ & $\$$ & $1,333.22$ & $\$$ & $3,045.56$ & $\$$ & 232.50 & $\$ 1,233.54$ & $\$$ & $535,912.89$ \\
\hline Mes 312 & $\$ 11,085.22$ & $\$$ & $1,333.22$ & $\$$ & $3,045.56$ & $\$$ & 232.50 & $\$ 1,247.03$ & $\$$ & $541,771.20$ \\
\hline Mes 313 & $\$ 11,251.50$ & $\$$ & $1,353.22$ & $\$$ & $3,045.56$ & $\$$ & 232.50 & $\$ 1,260.59$ & $\$$ & $547,663.07$ \\
\hline Mes 314 & $\$ 11,251.50$ & $\$$ & $1,353.22$ & $\$$ & $3,045.56$ & $\$$ & 232.50 & $\$ 1,274.18$ & $\$$ & $553,568.53$ \\
\hline Mes 315 & $\$ 11,251.50$ & $\$$ & $1,353.22$ & $\$$ & $3,045.56$ & $\$$ & 232.50 & $\$ 1,287.81$ & $\$$ & $559,487.62$ \\
\hline Mes 316 & $\$ 11,251.50$ & $\$$ & $1,353.22$ & $\$$ & $3,045.56$ & $\$$ & 232.50 & $\$ 1,301.46$ & $\$$ & $565,420.36$ \\
\hline Mes 317 & $\$ 11,251.50$ & $\$$ & $1,353.22$ & $\$$ & $3,045.56$ & $\$$ & 232.50 & $\$ 1,315.15$ & $\$$ & $571,366.79$ \\
\hline Mes 318 & $\$ 11,251.50$ & $\$$ & $1,353.22$ & $\$$ & $3,045.56$ & $\$$ & 232.50 & $\$ 1,328.87$ & $\$$ & $577,326.94$ \\
\hline Mes 319 & $\$ 11,251.50$ & $\$$ & $1,353.22$ & $\$$ & $3,045.56$ & $\$$ & 232.50 & $\$ 1,342.62$ & $\$$ & $583,300.83$ \\
\hline Mes 320 & $\$ 11,251.50$ & $\$$ & $1,353.22$ & $\$$ & $3,045.56$ & $\$$ & 232.50 & $\$ 1,356.40$ & $\$$ & $589,288.51$ \\
\hline Mes 321 & $\$ 11,251.50$ & $\$$ & $1,353.22$ & $\$$ & $3,045.56$ & $\$$ & 232.50 & $\$ 1,370.22$ & $\$$ & $595,290.01$ \\
\hline Mes 322 & $\$ 11,251.50$ & $\$$ & $1,353.22$ & $\$$ & $3,045.56$ & $\$$ & 232.50 & $\$ 1,384.06$ & $\$$ & $601,305.35$ \\
\hline Mes 323 & $\$ 11,251.50$ & $\$$ & $1,353.22$ & $\$$ & $3,045.56$ & $\$$ & 232.50 & $\$ 1,397.94$ & $\$$ & $607,334.57$ \\
\hline Mes 324 & $\$ 11,251.50$ & $\$$ & $1,353.22$ & $\$$ & $3,045.56$ & $\$$ & 232.50 & $\$ 1,411.85$ & $\$$ & $613,377.69$ \\
\hline Mes 325 & $\$ 11,420.27$ & $\$$ & $1,373.52$ & $\$$ & $3,045.56$ & $\$$ & 232.50 & $\$ 1,425.84$ & $\$$ & $619,455.11$ \\
\hline Mes 326 & $\$ 11,420.27$ & $\$$ & $1,373.52$ & $\$$ & $3,045.56$ & $\$$ & 232.50 & $\$ 1,439.86$ & $\$$ & $625,546.55$ \\
\hline Mes 327 & $\$ 11,420.27$ & $\$$ & $1,373.52$ & $\$$ & $3,045.56$ & $\$$ & 232.50 & $\$ 1,453.91$ & $\$$ & $631,652.03$ \\
\hline Mes 328 & $\$ 11,420.27$ & $\$$ & $1,373.52$ & $\$$ & $3,045.56$ & $\$$ & 232.50 & $\$ 1,468.00$ & $\$$ & $637,771.61$ \\
\hline Mes 329 & $\$ 11,420.27$ & $\$$ & $1,373.52$ & $\$$ & $3,045.56$ & $\$$ & 232.50 & $\$ 1,482.12$ & $\$$ & $643,905.30$ \\
\hline Mes 330 & $\$ 11,420.27$ & $\$$ & $1,373.52$ & $\$$ & $3,045.56$ & $\$$ & 232.50 & $\$ 1,496.27$ & $\$$ & $650,053.15$ \\
\hline Mes 331 & $\$ 11,420.27$ & $\$$ & $1,373.52$ & $\$$ & $3,045.56$ & $\$$ & 232.50 & $\$ 1,510.45$ & $\$$ & $656,215.18$ \\
\hline
\end{tabular}




\begin{tabular}{|c|c|c|c|c|c|c|c|c|c|c|}
\hline Mes 332 & $\$ 11,420.27$ & $\$$ & $1,373.52$ & $\$$ & $3,045.56$ & $\$$ & 232.50 & $\$ 1,524.67$ & $\$$ & $662,391.42$ \\
\hline Mes 333 & $\$ 11,420.27$ & $\$$ & $1,373.52$ & $\$$ & $3,045.56$ & $\$$ & 232.50 & $\$ 1,538.92$ & $\$$ & $668,581.91$ \\
\hline Mes 334 & $\$ 11,420.27$ & $\$$ & $1,373.52$ & $\$$ & $3,045.56$ & $\$$ & 232.50 & $\$ 1,553.20$ & $\$$ & $674,786.69$ \\
\hline Mes 335 & $\$ 11,420.27$ & $\$$ & $1,373.52$ & $\$$ & $3,045.56$ & $\$$ & 232.50 & $\$ 1,567.51$ & $\$$ & $681,005.78$ \\
\hline Mes 336 & $\$ 11,420.27$ & $\$$ & $1,373.52$ & $\$$ & $3,045.56$ & $\$$ & 232.50 & $\$ 1,581.86$ & $\$$ & $687,239.22$ \\
\hline Mes 337 & $\$ 11,591.58$ & $\$$ & $1,394.12$ & $\$$ & $3,045.56$ & $\$$ & 232.50 & $\$ 1,596.29$ & $\$$ & $693,507.69$ \\
\hline Mes 338 & $\$ 11,591.58$ & $\$$ & $1,394.12$ & $\$$ & $3,045.56$ & $\$$ & 232.50 & $\$ 1,610.75$ & $\$$ & $699,790.62$ \\
\hline Mes 339 & $\$ 11,591.58$ & $\$$ & $1,394.12$ & $\$$ & $3,045.56$ & $\$$ & 232.50 & $\$ 1,625.25$ & $\$$ & $706,088.04$ \\
\hline Mes 340 & $\$ 11,591.58$ & $\$$ & $1,394.12$ & $\$$ & $3,045.56$ & $\$$ & 232.50 & $\$ 1,639.78$ & $\$$ & $712,400.00$ \\
\hline Mes 341 & $\$ 11,591.58$ & $\$$ & $1,394.12$ & $\$$ & $3,045.56$ & $\$$ & 232.50 & $\$ 1,654.34$ & $\$$ & $718,726.51$ \\
\hline Mes 342 & $\$ 11,591.58$ & $\$$ & $1,394.12$ & $\$$ & $3,045.56$ & $\$$ & 232.50 & $\$ 1,668.93$ & $\$$ & $725,067.63$ \\
\hline Mes 343 & $\$ 11,591.58$ & $\$$ & $1,394.12$ & $\$$ & $3,045.56$ & $\$$ & 232.50 & $\$ 1,683.56$ & $\$$ & $731,423.37$ \\
\hline Mes 344 & $\$ 11,591.58$ & $\$$ & $1,394.12$ & $\$$ & $3,045.56$ & $\$$ & 232.50 & $\$ 1,698.23$ & $\$$ & $737,793.77$ \\
\hline Mes 345 & $\$ 11,591.58$ & $\$$ & $1,394.12$ & $\$$ & $3,045.56$ & $\$$ & 232.50 & $\$ 1,712.92$ & $\$$ & $744,178.88$ \\
\hline Mes 346 & $\$ 11,591.58$ & $\$$ & $1,394.12$ & $\$$ & $3,045.56$ & $\$$ & 232.50 & $\$ 1,727.65$ & $\$$ & $750,578.71$ \\
\hline Mes 347 & $\$ 11,591.58$ & $\$$ & $1,394.12$ & $\$$ & $3,045.56$ & $\$$ & 232.50 & $\$ 1,742.42$ & $\$$ & $756,993.31$ \\
\hline Mes 348 & $\$ 11,591.58$ & $\$$ & $1,394.12$ & $\$$ & $3,045.56$ & $\$$ & 232.50 & $\$ 1,757.22$ & $\$$ & $763,422.71$ \\
\hline Mes 349 & $\$ 11,765.45$ & $\$$ & $1,415.03$ & $\$$ & $3,045.56$ & $\$$ & 232.50 & $\$ 1,772.10$ & $\$$ & $769,887.90$ \\
\hline Mes 350 & $\$ 11,765.45$ & $\$$ & $1,415.03$ & $\$$ & $3,045.56$ & $\$$ & 232.50 & $\$ 1,787.01$ & $\$$ & $776,368.00$ \\
\hline Mes 351 & $\$ 11,765.45$ & $\$$ & $1,415.03$ & $\$$ & $3,045.56$ & $\$$ & 232.50 & $\$ 1,801.97$ & $\$$ & $782,863.06$ \\
\hline Mes 352 & $\$ 11,765.45$ & $\$$ & $1,415.03$ & $\$$ & $3,045.56$ & $\$$ & 232.50 & $\$ 1,816.95$ & $\$$ & $789,373.10$ \\
\hline Mes 353 & $\$ 11,765.45$ & $\$$ & $1,415.03$ & $\$$ & $3,045.56$ & $\$$ & 232.50 & $\$ 1,831.97$ & $\$$ & $795,898.16$ \\
\hline Mes 354 & $\$ 11,765.45$ & $\$$ & $1,415.03$ & $\$$ & $3,045.56$ & $\$$ & 232.50 & $\$ 1,847.02$ & $\$$ & $802,438.27$ \\
\hline Mes 355 & $\$ 11,765.45$ & $\$$ & $1,415.03$ & $\$$ & $3,045.56$ & $\$$ & 232.50 & $\$ 1,862.11$ & $\$$ & $808,993.47$ \\
\hline Mes 356 & $\$ 11,765.45$ & $\$$ & $1,415.03$ & $\$$ & $3,045.56$ & $\$$ & 232.50 & $\$ 1,877.23$ & $\$$ & $815,563.80$ \\
\hline Mes 357 & $\$ 11,765.45$ & $\$$ & $1,415.03$ & $\$$ & $3,045.56$ & $\$$ & 232.50 & $\$ 1,892.39$ & $\$$ & $822,149.28$ \\
\hline Mes 358 & $\$ 11,765.45$ & $\$$ & $1,415.03$ & $\$$ & $3,045.56$ & $\$$ & 232.50 & $\$ 1,907.59$ & $\$$ & $828,749.96$ \\
\hline Mes 359 & $\$ 11,765.45$ & $\$$ & $1,415.03$ & $\$$ & $3,045.56$ & $\$$ & 232.50 & $\$ 1,922.81$ & $\$$ & $835,365.86$ \\
\hline Mes 360 & $\$ 11,765.45$ & $\$$ & $1,415.03$ & $\$$ & $3,045.56$ & $\$$ & 232.50 & $\$ 1,938.08$ & $\$$ & $841,997.03$ \\
\hline Mes 361 & $\$ 11,941.93$ & $\$$ & $1,436.26$ & $\$$ & $3,045.56$ & $\$$ & 232.50 & $\$ 1,953.42$ & $\$$ & $848,664.77$ \\
\hline Mes 362 & $\$ 11,941.93$ & $\$$ & $1,436.26$ & $\$$ & $3,045.56$ & $\$$ & 232.50 & $\$ 1,968.81$ & $\$$ & $855,347.90$ \\
\hline Mes 363 & $\$ 11,941.93$ & $\$$ & $1,436.26$ & $\$$ & $3,045.56$ & $\$$ & 232.50 & $\$ 1,984.23$ & $\$$ & $862,046.44$ \\
\hline Mes 364 & $\$ 11,941.93$ & $\$$ & $1,436.26$ & $\$$ & $3,045.56$ & $\$$ & 232.50 & $\$ 1,999.68$ & $\$$ & $868,760.44$ \\
\hline Mes 365 & $\$ 11,941.93$ & $\$$ & $1,436.26$ & $\$$ & $3,045.56$ & $\$$ & 232.50 & $\$ 2,015.17$ & $\$$ & $875,489.92$ \\
\hline Mes 366 & $\$ 11,941.93$ & $\$$ & $1,436.26$ & $\$$ & $3,045.56$ & $\$$ & 232.50 & $\$ 2,030.70$ & $\$$ & $882,234.93$ \\
\hline Mes 367 & $\$ 11,941.93$ & $\$$ & $1,436.26$ & $\$$ & $3,045.56$ & $\$$ & 232.50 & $\$ 2,046.26$ & $\$$ & $888,995.51$ \\
\hline Mes 368 & $\$ 11,941.93$ & $\$$ & $1,436.26$ & $\$$ & $3,045.56$ & $\$$ & 232.50 & $\$ 2,061.85$ & $\$$ & $895,771.68$ \\
\hline Mes 369 & $\$ 11,941.93$ & $\$$ & $1,436.26$ & $\$$ & $3,045.56$ & $\$$ & 232.50 & $\$ 2,077.49$ & $\$$ & $902,563.48$ \\
\hline Mes 370 & $\$ 11,941.93$ & $\$$ & $1,436.26$ & $\$$ & $3,045.56$ & $\$$ & 232.50 & $\$ 2,093.16$ & $\$$ & $909,370.95$ \\
\hline Mes 371 & $\$ 11,941.93$ & $\$$ & $1,436.26$ & $\$$ & $3,045.56$ & $\$$ & 232.50 & $\$ 2,108.86$ & $\$$ & $916,194.13$ \\
\hline Mes 372 & $\$ 11,941.93$ & $\$$ & $1,436.26$ & $\$$ & $3,045.56$ & $\$$ & 232.50 & $\$ 2,124.60$ & $\$$ & $923,033.05$ \\
\hline
\end{tabular}




\begin{tabular}{|c|c|c|c|c|c|c|c|c|c|c|c|}
\hline Mes 373 & $\$$ & $12,121.06$ & $\$$ & $1,457.80$ & $\$$ & $3,045.56$ & $\$$ & 232.50 & $\$ 2,140.43$ & $\$$ & $929,909.34$ \\
\hline Mes 374 & $\$$ & $12,121.06$ & $\$$ & $1,457.80$ & $\$$ & $3,045.56$ & $\$$ & 232.50 & $\$ 2,156.29$ & $\$$ & $936,801.50$ \\
\hline Mes 375 & $\$$ & $12,121.06$ & $\$$ & $1,457.80$ & $\$$ & $3,045.56$ & $\$$ & 232.50 & $\$ 2,172.20$ & $\$$ & $943,709.55$ \\
\hline Mes 376 & $\$$ & $12,121.06$ & $\$$ & $1,457.80$ & $\$$ & $3,045.56$ & $\$$ & 232.50 & $\$ 2,188.13$ & $\$$ & $950,633.54$ \\
\hline Mes 377 & $\$$ & $12,121.06$ & $\$$ & $1,457.80$ & $\$$ & $3,045.56$ & $\$$ & 232.50 & $\$ 2,204.11$ & $\$$ & $957,573.51$ \\
\hline Mes 378 & $\$$ & $12,121.06$ & $\$$ & $1,457.80$ & $\$$ & $3,045.56$ & $\$$ & 232.50 & $\$ 2,220.12$ & $\$$ & $964,529.49$ \\
\hline Mes 379 & $\$$ & $12,121.06$ & $\$$ & $1,457.80$ & $\$$ & $3,045.56$ & $\$$ & 232.50 & $\$ 2,236.17$ & $\$$ & $971,501.52$ \\
\hline Mes 380 & $\$$ & $12,121.06$ & $\$$ & $1,457.80$ & $\$$ & $3,045.56$ & $\$$ & 232.50 & $\$ 2,252.25$ & $\$$ & $978,489.63$ \\
\hline Mes 381 & $\$$ & $12,121.06$ & $\$$ & $1,457.80$ & $\$$ & $3,045.56$ & $\$$ & 232.50 & $\$ 2,268.37$ & $\$$ & $985,493.86$ \\
\hline Mes 382 & $\$$ & $12,121.06$ & $\$$ & $1,457.80$ & $\$$ & $3,045.56$ & $\$$ & 232.50 & $\$ 2,284.53$ & $\$$ & $992,514.25$ \\
\hline Mes 383 & $\$$ & $12,121.06$ & $\$$ & $1,457.80$ & $\$$ & $3,045.56$ & $\$$ & 232.50 & $\$ 2,300.73$ & $\$$ & $999,550.84$ \\
\hline Mes 384 & $\$$ & $12,121.06$ & $\$$ & $1,457.80$ & $\$$ & $3,045.56$ & $\$$ & 232.50 & $\$ 2,316.96$ & $\$$ & $1,006,603.66$ \\
\hline Mes 385 & $\$$ & $12,302.88$ & $\$$ & $1,479.67$ & $\$$ & $3,045.56$ & $\$$ & 232.50 & $\$ 2,333.28$ & $\$$ & $1,013,694.68$ \\
\hline Mes 386 & $\$$ & $12,302.88$ & $\$$ & $1,479.67$ & $\$$ & $3,045.56$ & $\$$ & 232.50 & $\$ 2,349.64$ & $\$$ & $1,020,802.05$ \\
\hline Mes 387 & $\$$ & $12,302.88$ & $\$$ & $1,479.67$ & $\$$ & $3,045.56$ & $\$$ & 232.50 & $\$ 2,366.04$ & $\$$ & $1,027,925.82$ \\
\hline Mes 388 & $\$$ & $12,302.88$ & $\$$ & $1,479.67$ & $\$$ & $3,045.56$ & $\$$ & 232.50 & $\$ 2,382.48$ & $\$$ & $1,035,066.02$ \\
\hline Mes 389 & $\$$ & $12,302.88$ & $\$$ & $1,479.67$ & $\$$ & $3,045.56$ & $\$$ & 232.50 & $\$ 2,398.95$ & $\$$ & $1,042,222.70$ \\
\hline Mes 390 & $\$$ & $12,302.88$ & $\$$ & $1,479.67$ & $\$$ & $3,045.56$ & $\$$ & 232.50 & $\$ 2,415.46$ & $\$$ & $1,049,395.88$ \\
\hline Mes 391 & $\$$ & $12,302.88$ & $\$$ & $1,479.67$ & $\$$ & $3,045.56$ & $\$$ & 232.50 & $\$ 2,432.01$ & $\$$ & $1,056,585.62$ \\
\hline Mes 392 & $\$$ & $12,302.88$ & $\$$ & $1,479.67$ & $\$$ & $3,045.56$ & $\$$ & 232.50 & $\$ 2,448.60$ & $\$$ & $1,063,791.94$ \\
\hline Mes 393 & $\$$ & $12,302.88$ & $\$$ & $1,479.67$ & $\$$ & $3,045.56$ & $\$$ & 232.50 & $\$ 2,465.22$ & $\$$ & $1,071,014.89$ \\
\hline Mes 394 & $\$$ & $12,302.88$ & $\$$ & $1,479.67$ & $\$$ & $3,045.56$ & $\$$ & 232.50 & $\$ 2,481.89$ & $\$$ & $1,078,254.51$ \\
\hline Mes 395 & $\$$ & $12,302.88$ & $\$$ & $1,479.67$ & $\$$ & $3,045.56$ & $\$$ & 232.50 & $\$ 2,498.59$ & $\$$ & $1,085,510.82$ \\
\hline Mes 396 & $\$$ & $12,302.88$ & $\$$ & $1,479.67$ & $\$$ & $3,045.56$ & $\$$ & 232.50 & $\$ 2,515.33$ & $\$$ & $1,092,783.88$ \\
\hline Mes 397 & $\$$ & $12,487.42$ & $\$$ & $1,501.86$ & & & $\$$ & 232.50 & $\$ 2,525.13$ & $\$$ & $1,097,043.37$ \\
\hline Mes 398 & $\$$ & $12,487.42$ & $\$$ & $1,501.86$ & & & $\$$ & 232.50 & $\$ 2,534.96$ & $\$$ & $1,101,312.70$ \\
\hline Mes 399 & $\$$ & $12,487.42$ & $\$$ & $1,501.86$ & & & $\$$ & 232.50 & $\$ 2,544.81$ & $\$$ & $1,105,591.87$ \\
\hline Mes 400 & $\$$ & $12,487.42$ & $\$$ & $1,501.86$ & & & $\$$ & 232.50 & $\$ 2,554.68$ & $\$$ & $1,109,880.91$ \\
\hline Mes 401 & $\$$ & $12,487.42$ & $\$$ & $1,501.86$ & & & $\$$ & 232.50 & $\$ 2,564.58$ & $\$$ & $1,114,179.85$ \\
\hline Mes 402 & $\$$ & $12,487.42$ & $\$$ & $1,501.86$ & & & $\$$ & 232.50 & $\$ 2,574.50$ & $\$$ & $1,118,488.71$ \\
\hline Mes 403 & $\$$ & $12,487.42$ & $\$$ & $1,501.86$ & & & $\$$ & 232.50 & $\$ 2,584.44$ & $\$$ & $1,122,807.51$ \\
\hline Mes 404 & $\$$ & $12,487.42$ & $\$$ & $1,501.86$ & & & $\$$ & 232.50 & $\$ 2,594.40$ & $\$$ & $1,127,136.27$ \\
\hline Mes 405 & $\$$ & $12,487.42$ & $\$$ & $1,501.86$ & & & $\$$ & 232.50 & $\$ 2,604.39$ & $\$$ & $1,131,475.02$ \\
\hline Mes 406 & $\$$ & $12,487.42$ & $\$$ & $1,501.86$ & & & $\$$ & 232.50 & $\$ 2,614.40$ & $\$$ & $1,135,823.78$ \\
\hline Mes 407 & $\$$ & $12,487.42$ & $\$$ & $1,501.86$ & & & $\$$ & 232.50 & $\$ 2,624.43$ & $\$$ & $1,140,182.57$ \\
\hline Mes 408 & $\$$ & $12,487.42$ & $\$$ & $1,501.86$ & & & $\$$ & 232.50 & $\$ 2,634.49$ & $\$$ & $1,144,551.42$ \\
\hline Mes 409 & $\$$ & $12,674.73$ & $\$$ & $1,524.39$ & & & $\$$ & 232.50 & $\$ 2,644.62$ & $\$$ & $1,148,952.93$ \\
\hline Mes 410 & $\$$ & $12,674.73$ & $\$$ & $1,524.39$ & & & $\$$ & 232.50 & $\$ 2,654.77$ & $\$$ & $1,153,364.59$ \\
\hline Mes 411 & $\$$ & $12,674.73$ & $\$$ & $1,524.39$ & & & $\$$ & 232.50 & $\$ 2,664.95$ & $\$$ & $1,157,786.43$ \\
\hline Mes 412 & $\$$ & $12,674.73$ & $\$$ & $1,524.39$ & & & $\$$ & 232.50 & $\$ 2,675.15$ & $\$$ & $1,162,218.47$ \\
\hline Mes 413 & $\$$ & $12,674.73$ & $\$$ & $1,524.39$ & & & $\$$ & 232.50 & $\$ 2,685.38$ & $\$$ & $1,166,660.74$ \\
\hline
\end{tabular}




\begin{tabular}{|c|c|c|c|c|c|c|c|c|}
\hline Mes 414 & $\$ \quad 12,674.73$ & $\$$ & $1,524.39$ & $\$$ & 232.50 & $\$ 2,695.62$ & $\$$ & $1,171,113.25$ \\
\hline Mes 415 & $\$ 12,674.73$ & $\$$ & $1,524.39$ & $\$$ & 232.50 & $\$ 2,705.90$ & $\$$ & $1,175,576.04$ \\
\hline Mes 416 & $\$ 12,674.73$ & $\$$ & $1,524.39$ & $\$$ & 232.50 & $\$ 2,716.19$ & $\$$ & $1,180,049.12$ \\
\hline Mes 417 & $\$ 12,674.73$ & $\$$ & $1,524.39$ & $\$$ & 232.50 & $\$ 2,726.51$ & $\$$ & $1,184,532.53$ \\
\hline Mes 418 & $\$ 12,674.73$ & $\$$ & $1,524.39$ & $\$$ & 232.50 & $\$ 2,736.86$ & $\$$ & $1,189,026.27$ \\
\hline Mes 419 & $\$ 12,674.73$ & $\$$ & $1,524.39$ & $\$$ & 232.50 & $\$ 2,747.22$ & $\$$ & $1,193,530.39$ \\
\hline Mes 420 & $\$ 12,674.73$ & $\$$ & $1,524.39$ & $\$$ & 232.50 & $\$ 2,757.62$ & $\$$ & $1,198,044.89$ \\
\hline Mes 421 & $\$ 12,864.85$ & $\$$ & $1,547.26$ & $\$$ & 232.50 & $\$ 2,768.08$ & $\$$ & $1,202,592.73$ \\
\hline Mes 422 & $\$ 12,864.85$ & $\$$ & $1,547.26$ & $\$$ & 232.50 & $\$ 2,778.58$ & $\$$ & $1,207,151.06$ \\
\hline Mes 423 & $\$ 12,864.85$ & $\$$ & $1,547.26$ & $\$$ & 232.50 & $\$ 2,789.09$ & $\$$ & $1,211,719.91$ \\
\hline Mes 424 & $\$ \quad 12,864.85$ & $\$$ & $1,547.26$ & $\$$ & 232.50 & $\$ 2,799.63$ & $\$$ & $1,216,299.30$ \\
\hline Mes 425 & $\$ 12,864.85$ & $\$$ & $1,547.26$ & $\$$ & 232.50 & $\$ 2,810.20$ & $\$$ & $1,220,889.25$ \\
\hline Mes 426 & $\$ 12,864.85$ & $\$$ & $1,547.26$ & $\$$ & 232.50 & $\$ 2,820.79$ & $\$$ & $1,225,489.79$ \\
\hline Mes 427 & $\$ 12,864.85$ & $\$$ & $1,547.26$ & $\$$ & 232.50 & $\$ 2,831.40$ & $\$$ & $1,230,100.95$ \\
\hline Mes 428 & $\$ 12,864.85$ & $\$$ & $1,547.26$ & $\$$ & 232.50 & $\$ 2,842.04$ & $\$$ & $1,234,722.74$ \\
\hline Mes 429 & $\$ 12,864.85$ & $\$$ & $1,547.26$ & $\$$ & 232.50 & $\$ 2,852.70$ & $\$$ & $1,239,355.20$ \\
\hline Mes 430 & $\$ 12,864.85$ & $\$$ & $1,547.26$ & $\$$ & 232.50 & $\$ 2,863.39$ & $\$$ & $1,243,998.35$ \\
\hline Mes 431 & $\$ 12,864.85$ & $\$$ & $1,547.26$ & $\$$ & 232.50 & $\$ 2,874.10$ & $\$$ & $1,248,652.20$ \\
\hline Mes 432 & $\$ 12,864.85$ & $\$$ & $1,547.26$ & $\$$ & 232.50 & $\$ 2,884.84$ & $\$$ & $1,253,316.80$ \\
\hline Mes 433 & $\$ \quad 13,057.83$ & $\$$ & $1,570.46$ & $\$$ & 232.50 & $\$ 2,895.65$ & $\$$ & $1,258,015.42$ \\
\hline Mes 434 & $\$ 13,057.83$ & $\$$ & $1,570.46$ & $\$$ & 232.50 & $\$ 2,906.49$ & $\$$ & $1,262,724.87$ \\
\hline Mes 435 & $\$ 13,057.83$ & $\$$ & $1,570.46$ & $\$$ & 232.50 & $\$ 2,917.36$ & $\$$ & $1,267,445.20$ \\
\hline Mes 436 & $\$ 13,057.83$ & $\$$ & $1,570.46$ & $\$$ & 232.50 & $\$ 2,928.25$ & $\$$ & $1,272,176.41$ \\
\hline Mes 437 & $\$ 13,057.83$ & $\$$ & $1,570.46$ & $\$$ & 232.50 & $\$ 2,939.16$ & $\$$ & $1,276,918.54$ \\
\hline Mes 438 & $\$ 13,057.83$ & $\$$ & $1,570.46$ & $\$$ & 232.50 & $\$ 2,950.10$ & $\$$ & $1,281,671.61$ \\
\hline Mes 439 & $\$ \quad 13,057.83$ & $\$$ & $1,570.46$ & $\$$ & 232.50 & $\$ 2,961.07$ & $\$$ & $1,286,435.64$ \\
\hline Mes 440 & $\$ 13,057.83$ & $\$$ & $1,570.46$ & $\$$ & 232.50 & $\$ 2,972.06$ & $\$$ & $1,291,210.67$ \\
\hline Mes 441 & $\$ 13,057.83$ & $\$$ & $1,570.46$ & $\$$ & 232.50 & $\$ 2,983.08$ & $\$$ & $1,295,996.71$ \\
\hline Mes 442 & $\$ 13,057.83$ & $\$$ & $1,570.46$ & $\$$ & 232.50 & $\$ 2,994.12$ & $\$$ & $1,300,793.79$ \\
\hline Mes 443 & $\$ 13,057.83$ & $\$$ & $1,570.46$ & $\$$ & 232.50 & $\$ 3,005.19$ & $\$$ & $1,305,601.94$ \\
\hline Mes 444 & $\$ 13,057.83$ & $\$$ & $1,570.46$ & $\$$ & 232.50 & $\$ 3,016.28$ & $\$$ & $1,310,421.19$ \\
\hline Mes 445 & $\$ 13,253.69$ & $\$$ & $1,594.02$ & $\$$ & 232.50 & $\$ 3,027.45$ & $\$$ & $1,315,275.16$ \\
\hline Mes 446 & $\$ 13,253.69$ & $\$$ & $1,594.02$ & $\$$ & 232.50 & $\$ 3,038.65$ & $\$$ & $1,320,140.33$ \\
\hline Mes 447 & $\$ 13,253.69$ & $\$$ & $1,594.02$ & $\$$ & 232.50 & $\$ 3,049.87$ & $\$$ & $1,325,016.73$ \\
\hline Mes 448 & $\$ \quad 13,253.69$ & $\$$ & $1,594.02$ & $\$$ & 232.50 & $\$ 3,061.12$ & $\$$ & $1,329,904.37$ \\
\hline Mes 449 & $\$ \quad 13,253.69$ & $\$$ & $1,594.02$ & $\$$ & 232.50 & $\$ 3,072.40$ & $\$$ & $1,334,803.30$ \\
\hline Mes 450 & $\$ 13,253.69$ & $\$$ & $1,594.02$ & $\$$ & 232.50 & $\$ 3,083.70$ & $\$$ & $1,339,713.52$ \\
\hline Mes 451 & $\$ 13,253.69$ & $\$$ & $1,594.02$ & $\$$ & 232.50 & $\$ 3,095.03$ & $\$$ & $1,344,635.07$ \\
\hline Mes 452 & $\$ 13,253.69$ & $\$$ & $1,594.02$ & $\$$ & 232.50 & $\$ 3,106.39$ & $\$$ & $1,349,567.98$ \\
\hline Mes 453 & $\$ \quad 13,253.69$ & $\$$ & $1,594.02$ & $\$$ & 232.50 & $\$ 3,117.77$ & $\$$ & $1,354,512.27$ \\
\hline Mes 454 & $\$ 13,253.69$ & $\$$ & $1,594.02$ & $\$$ & 232.50 & $\$ 3,129.17$ & $\$$ & $1,359,467.96$ \\
\hline
\end{tabular}




\begin{tabular}{|c|c|c|c|c|c|c|c|c|}
\hline Mes 455 & $\$ 13,253.69$ & $\$$ & $1,594.02$ & $\$$ & 232.50 & $\$ 3,140.61$ & $\$$ & $1,364,435.09$ \\
\hline Mes 456 & $\$ 13,253.69$ & $\$$ & $1,594.02$ & $\$$ & 232.50 & $\$ 3,152.07$ & $\$$ & $1,369,413.68$ \\
\hline Mes 457 & $\$ 13,452.50$ & $\$$ & $1,617.93$ & $\$$ & 232.50 & $\$ 3,163.61$ & $\$$ & $1,374,427.71$ \\
\hline Mes 458 & $\$ 13,452.50$ & $\$$ & $1,617.93$ & $\$$ & 232.50 & $\$ 3,175.17$ & $\$$ & $1,379,453.32$ \\
\hline Mes 459 & $\$ 13,452.50$ & $\$$ & $1,617.93$ & $\$$ & 232.50 & $\$ 3,186.77$ & $\$$ & $1,384,490.52$ \\
\hline Mes 460 & $\$ 13,452.50$ & $\$$ & $1,617.93$ & $\$$ & 232.50 & $\$ 3,198.39$ & $\$$ & $1,389,539.34$ \\
\hline Mes 461 & $\$ 13,452.50$ & $\$$ & $1,617.93$ & $\$$ & 232.50 & $\$ 3,210.04$ & $\$$ & $1,394,599.81$ \\
\hline Mes 462 & $\$ 13,452.50$ & $\$$ & $1,617.93$ & $\$$ & 232.50 & $\$ 3,221.71$ & $\$$ & $1,399,671.96$ \\
\hline Mes 463 & $\$ 13,452.50$ & $\$$ & $1,617.93$ & $\$$ & 232.50 & $\$ 3,233.41$ & $\$$ & $1,404,755.81$ \\
\hline Mes 464 & $\$ 13,452.50$ & $\$$ & $1,617.93$ & $\$$ & 232.50 & $\$ 3,245.14$ & $\$$ & $1,409,851.38$ \\
\hline Mes 465 & $\$ 13,452.50$ & $\$$ & $1,617.93$ & $\$$ & 232.50 & $\$ 3,256.90$ & $\$$ & $1,414,958.71$ \\
\hline Mes 466 & $\$ 13,452.50$ & $\$$ & $1,617.93$ & $\$$ & 232.50 & $\$ 3,268.68$ & $\$$ & $1,420,077.83$ \\
\hline Mes 467 & $\$ 13,452.50$ & $\$$ & $1,617.93$ & $\$$ & 232.50 & $\$ 3,280.49$ & $\$$ & $1,425,208.75$ \\
\hline Mes 468 & $\$ 13,452.50$ & $\$$ & $1,617.93$ & $\$$ & 232.50 & $\$ 3,292.33$ & $\$$ & $1,430,351.51$ \\
\hline Mes 469 & $\$ 13,654.29$ & $\$$ & $1,642.20$ & $\$$ & 232.50 & $\$ 3,304.25$ & $\$$ & $1,435,530.46$ \\
\hline Mes 470 & $\$ 13,654.29$ & $\$$ & $1,642.20$ & $\$$ & 232.50 & $\$ 3,316.20$ & $\$$ & $1,440,721.36$ \\
\hline Mes 471 & $\$ 13,654.29$ & $\$$ & $1,642.20$ & $\$$ & 232.50 & $\$ 3,328.17$ & $\$$ & $1,445,924.24$ \\
\hline Mes 472 & $\$ 13,654.29$ & $\$$ & $1,642.20$ & $\$$ & 232.50 & $\$ 3,340.18$ & $\$$ & $1,451,139.12$ \\
\hline Mes 473 & $\$ 13,654.29$ & $\$$ & $1,642.20$ & $\$$ & 232.50 & $\$ 3,352.21$ & $\$$ & $1,456,366.03$ \\
\hline Mes 474 & $\$ 13,654.29$ & $\$$ & $1,642.20$ & $\$$ & 232.50 & $\$ 3,364.27$ & $\$$ & $1,461,605.00$ \\
\hline Mes 475 & $\$ 13,654.29$ & $\$$ & $1,642.20$ & $\$$ & 232.50 & $\$ 3,376.35$ & $\$$ & $1,466,856.05$ \\
\hline Mes 476 & $\$ 13,654.29$ & $\$$ & $1,642.20$ & $\$$ & 232.50 & $\$ 3,388.47$ & $\$$ & $1,472,119.22$ \\
\hline Mes 477 & $\$ 13,654.29$ & $\$$ & $1,642.20$ & $\$$ & 232.50 & $\$ 3,400.61$ & $\$$ & $1,477,394.54$ \\
\hline Mes 478 & $\$ 13,654.29$ & $\$$ & $1,642.20$ & $\$$ & 232.50 & $\$ 3,412.78$ & $\$$ & $1,482,682.02$ \\
\hline Mes 479 & $\$ 13,654.29$ & $\$$ & $1,642.20$ & $\$$ & 232.50 & $\$ 3,424.98$ & $\$$ & $1,487,981.70$ \\
\hline Mes 480 & $\$ 13,654.29$ & $\$$ & $1,642.20$ & $\$$ & 232.50 & $\$ 3,437.21$ & $\$$ & $1,493,293.61$ \\
\hline
\end{tabular}

Fuente: Elaboración propia con datos de CONSAR (2019) y Ley de Seguro Social (2021) 